\title{
DECAY PARAMETERS OF AFTERSHOCK SEQUENCES GLOBALLY DISTRIBUTED
}

\author{
Tsapanos, T.M. ${ }^{1}$, Koravos, G. Ch. ${ }^{1}$, Plessa, A. ${ }^{2}$, Vythoulkas, N.K. ${ }^{1}$ \\ and Pitsonis, I.S. ${ }^{1}$ \\ ${ }^{1}$ Aristotle University of Thessaloniki, School of Geology, Geophsical Laboratory, \\ 54124 Thessaloniki,Greece,tsapanos@geo.auths.gr \\ ${ }^{2}$ National Observatory of Athens, Institute of Geodynamics, \\ 11810 Athens, a.plessa@gein.noa.gr
}

\begin{abstract}
The evaluation of the parameters $c$ and $k$ of the decay law of the aftershocks in an earthquake sequence has been carried out in this study. For this reason 170 seismic sequences globally distributed, during the time period 1964-1986, were performed. All of them modelled well by Omori's law. We estimated that the mean global values of and parameters, are 0.660 \pm 0.181 and $0.341 \pm 0.090$, respectively. The values of these parameters are also estimated for different regions of the world, west and east part of circum-Pacific rim, as well as for the Eurasia belt.The parameters $c$ and $k$ calculated for the various regions of the world found to be spread around the global average, although admittedly few exceptions to this generalization are also observed to exist.
\end{abstract}

Key words: c-parameter, $k$-parameter, aftershocks decay laws, west and east side of Pacific rim, Eurasia belt.

\section{Introduction and data used}

Aftershocks occurrence is usually attributed to the strain energy not released by main shock or its possible foreshocks. These can cause significant damage to buildings. Occasionally they can result in building collapse. This risk is highest for previously damaged buildings by the main shock. Statistical properties of aftershocks and foreshocks have been extensively studied for long time. Most of them dealt with the distribution of aftershocks and/or foreshocks in time, space and magnitude domains. The main properties of the aftershock sequences have been described by many authors (Utsu, 1961; Page, 1968; Ranalli, 1969; Kisslonger and Jones, 1991; Tsapanos, 1990a; Narteau, et al., 2002, Parsons, 2002; Felzer and Bronsky, 2006; Corral, 2007; Vinogradov, 2008, among others). Two main laws controlled for many years the distribution of the aftershock sequences: a) Omori's law and b) Bath's law.

Moment release rates during mainshocks compared with moment release rates during aftershocks sequences showed that the moment release rates of aftershock sequences are 30 times smaller than the maximum moment rate of the main shock (Kagan and Houston, 2005).

Tsapanos (1990a) listed his observations for 182 earthquake sequences, trying to establish a fresh expression for the so called Bath's law. These sequences occurred all over the world during 19641986. Only shallow earthquakes $(\mathrm{h} \leq 60 \mathrm{~km})$ with main shock magnitude $\mathrm{M} \geq 7.0$ are taken into ac- 
count from the database of ISC global earthquake catalogue. In a previous study (Tsapanos et al., 1994) used the complete data sets for the examined aftershock sequences (with aftershock magnitude $\mathrm{M} \geq 4.5$ ) and suggested that the completeness of the aftershocks is essential for such analysis. The possible incompleteness of the catalogs especially in the first time after the main shock plays a key role to the aftershock sequence processing (Lolli and Gasperini, 2006). The data of these sequences used in the present study. Distance (Utsu, 1969) and time (Tajima and Kanamori, 1985) conditions used to distinguish the aftershocks in any seismic sequence. The sequences occurred in oceans or have inadequate data for further analysis are eliminated from the present work. Only earthquake sequences occurred in the circum-Pacific rim and in the Eursia continent are finally taken into consideration, which consisted of 170 aftershock sequences.

\section{Decay law of aftershocks}

According to the work of Omori (1895) the aftershock rate is roughly proportional to the inverse of the time, $\mathrm{t}$, elapsed after the main shock:

In eq. (1) $\mathrm{c}$ and $\mathrm{k}$ are coefficients, while time $\mathrm{t}$ is the time since main shock origin and $\mathrm{n}(\mathrm{t})$ is the aftershock frequency measured over a certain time interval.

Kisslinger and Jones (1991) suggested that $\mathrm{k}$ is dependent on the total number of aftershocks in the sequence and $\mathrm{c}$ on the activity in the earliest part of the sequence.

Papazachos (1975) by using data from Greece, found that the cumulative frequency distribution $\mathrm{N}\left(\mathrm{T}_{\mathrm{i}}\right)$ of the time difference between main shock and the largest aftershock, was given by the relation:

Where $\mathrm{c}$ is the number of the earthquakes or the percentage of the events which occurred during the first day and $\mathrm{k}$ is the slope of the equation (2).

A data set of aftershocks sequences globally distributed, covered the time period 1904-1980, with main shock magnitude $M \geq 7.4$ were performed by Tsapanos et al. (1988). They found that the correlation between the probabilities $\mathrm{N}(\mathrm{T})$ of occurrence of the largest aftershock and the $\mathrm{T}$ ( $\mathrm{T}$ is the time between the main shock and its largest aftershock) show the best fit (Fig. 1). The obtained values of the parameters $\mathrm{c}$ and $\mathrm{k}$ were $0.647 \pm 0.020$ and $-0.299 \pm 0.010$, respectively.

Our data, as mentioned before, covered the circum-Pacific rim, as well as the Eurasia belt. The circumPacific rim separated, in two areas AREA1 and AREA2. The west side of the Pacific (AREA1) includes: Chile (1), northwest coasts of South America (2), Middle America (3), Mexico (4), west coasts of U.S.A. and Canada (5) and finally Alaska and Aleutian islands (6). The east side of Pacific (AREA2) includes: Kamchatka and Kurile islands (7), Japan (8), Taiwan (9), Marianas islands (10), Philippine islands (11), Sunda arc (12), Papua-Solomon islands (13), New Hebrides islands (14) and Fiji-Tonga and New Zealand (15). The division of the Pacific's regions is almost according to the one introduced by Tsapanos (1990b).

\section{Regional values}

Global average values of the parameters $\mathrm{c}$ and $\mathrm{k}$ were estimated and found that they are equal to $=0.660 \pm 0.181$ and $=-0.341 \pm 0.090$ (Fig. $2 \mathrm{a}$ and $2 \mathrm{~b}$ ). 


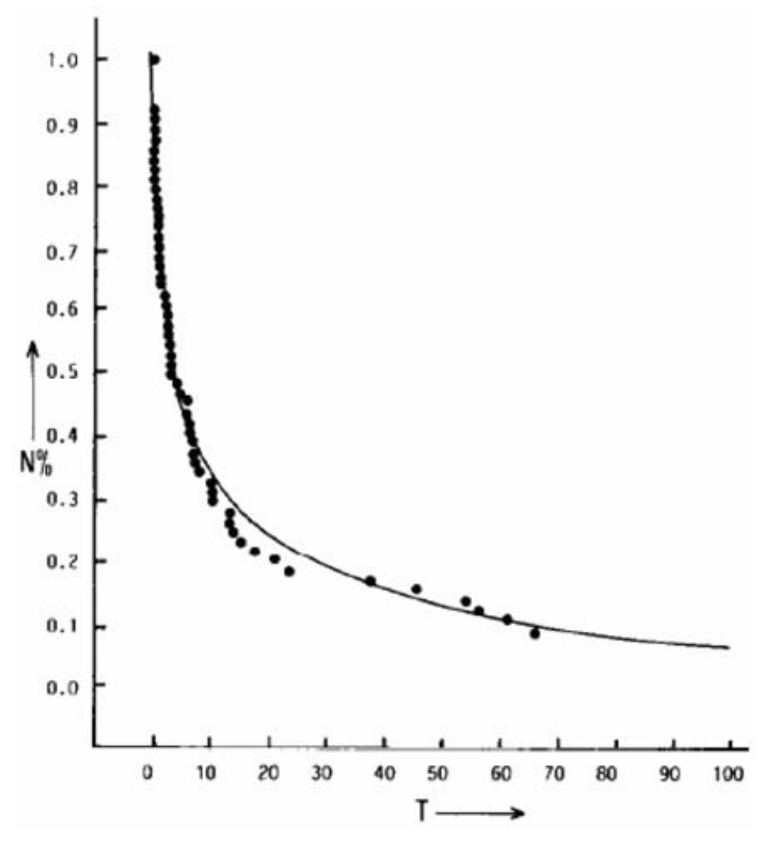

Fig. 1: Distribution of the probability $(\mathrm{N}(\mathrm{T})$ against $\mathrm{T}$, for the largest aftershocks which followed mainshocks with $\mathrm{M} \geq 7.4$ during the period 1904-1980 (after Tsapanos et al. 1988). (a)

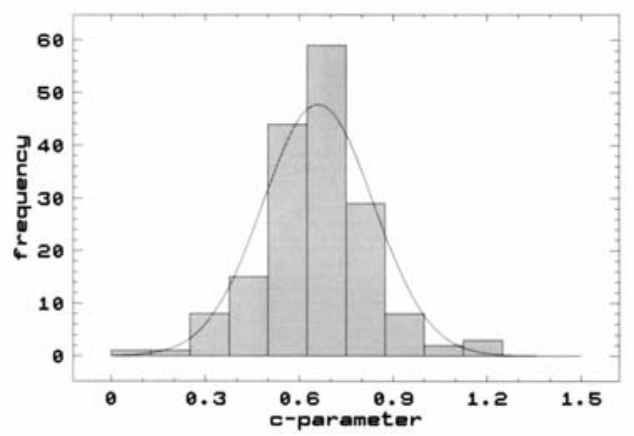

(b)

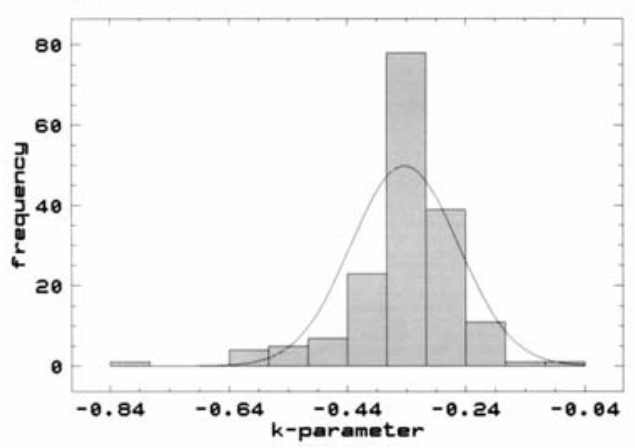

Fig. 2: The distribution of the average global values of the aftershock decay parameters: (a) c parameter and (b) k parameter.

The 170 aftershock sequences globally distributed were then separated in two groups. The first group belongs to the circum-Pacific rim, while the second one belongs to Eurasia. The obtained values of the parameters $\mathrm{c}$ and $\mathrm{k}$ are listed in Table (1).

The statistical T-test has been applied in order to verify the significance of the difference between the c-parameters of the two data groups. The results show that the parameter $t$ (of the T-test) is equal to -1.75436 which corresponds to a probability $\mathrm{PROB}=0.0847$. This means that the probability of the two groups to belong to the same population is about $\approx 8.5 \%$. This result indicates that the two groups are in some sense statistically significant. 
Table 1. The mean values and their standard deviation (sd) of the parameters $\mathrm{c}$ and $\mathrm{k}$ in the circumPacific rim and Eurasia belt.

\begin{tabular}{|c|c|c|}
\hline & circum-Pacific & Eurasia \\
\hline c-parameter+sd & $0.612+0.043$ & $0.691+0.116$ \\
\hline k-parameter+sd & $-0.319+0.007$ & $-0.340+0.048$ \\
\hline
\end{tabular}

Table 2. Regional values and their standard deviation (sd) of the parameters $\mathrm{c}$ and $\mathrm{k}$ in the seismically active regions of the circum-Pacific belt.

\begin{tabular}{|c|c|c|}
\hline Region & c+sd & k+sd \\
\hline West Pacific & & $-0.373+0.076$ \\
\hline Chile (1) & $0.660+0.108$ & $-0.321+0.057$ \\
\hline NW coasts of S. America (2) & $0.685+0.121$ & $-0.266+0.036$ \\
\hline Middle America (3) & $0.550+0.073$ & $-0.357+0.062$ \\
\hline Mexico (4) & $0.686+0.113$ & $-0.294+0.043$ \\
\hline W. coasts of USA \& Canada (5) & $0.531+0.101$ & $-0.348+0.042$ \\
\hline Alaska and Aleutian islands (6) & $0.727+0.117$ & $-0.349+0.071$ \\
\hline East Pacific & & $-0.338+0.062$ \\
\hline Kamchatka and Kurile islands (7) & $0.728+0.163$ & $-0.244+0.047$ \\
\hline Japan (8) & $0.620+0.160$ & $-0.252+0.032$ \\
\hline Taiwan (9) & $0.603+0.097$ & $-0.329+0.043$ \\
\hline Marianas islands (10) & $0.611+0.129$ & $-0.316+0.048$ \\
\hline Philippines islands (11) & $0.695+0.112$ & $-0.331+0.043$ \\
\hline Sunda arc (12) & $0.689+0.104$ & $-0.354+0.062$ \\
\hline Papua-Solomon islands (13) & $0.717+0.085$ & $-0.301+0.015$ \\
\hline New Hebrides islands (14) & $0.668+0.092$ & \\
\hline Fiji-Kermadec-Tonga- & $0.671+0.110$ & \\
\hline New Zealand (15) & & \\
\hline & & \\
\hline & & \\
\hline
\end{tabular}

In order to study these parameters in details a further division applied. This time we divided the circum-Pacific in two sides: a) the island arcs of the east Pacific (e.g. Japan, etc) and b) the west side (American continent mainly). Regional values of the parameters $\mathrm{c}$ and $\mathrm{k}$ are calculated for the regions around the circum-Pacific rim and are listed in Table (2).

The T-test has been applied again to check the statistical significance between the data of the east and west side of the circum-Pacific belt. The t parameter (of the T-test) is equal to 1.86812 and the $\mathrm{PROB}=6.4 \%$. From this result it can be interpreted that the mean c values of the two sides of the Pacific rim are different with a probability $\approx 94 \%$. 


\section{Discussion and Conclusions}

A first inspection to the above table (2) generally reveals that the parameters $\mathrm{c}$ and $\mathrm{k}$ have values around the average global values, although there are regions which do not follow this pattern, having values greater than or less than the global averages. Our discussion will be focused on the exceptions.

If we follow Kisslinger and Jones's (1991) suggestion that $\mathrm{k}$ is dependent on the total number of aftershocks in the sequence and c on the activity in the earliest part of the sequence we can lead to some conclusions about these aftershock parameters. Kagan and Houston (2005) suggested five reasons for non-zero c-parameter. It was introduced to explain, by the same authors, the seeming saturation of aftershock rate close to the origin time of a mainshock. The parameter $\mathrm{c}$ always found to be positive and typically ranges from 0.5 to 20 hours in empirical studies (Utsu, 1961; Reasenberg and Jones, 1989, 1994; Utsu et al. 1995) It was introduced, by the same authors, to explain the seeming saturation of aftershock rate close to the origin time of a mainshock. Shcherbakov, et al. (2006) taken into account three laws (Gutenberg \& Richter, Omori's and Bath's) and suggested that the cparameter plays the role of a characteristic time for establishment of Gutenberg-Richter scaling. This time increases systematically with a decreasing lower magnitude cutoff. The k-parameter slightly varies with the lower magnitude cutoff of the sequence.

Kamchatka and Kurile islands has the highest c value. This means that the aftershock sequences occurred in this region seem to be very active during the first times after the main shock occurrence. The value of the parameter $\mathrm{c}$ in Alaska and Aleutians as a whole region seems to be very active during the first times after the release of the main shock. However k parameter reveals that this is around the global value. One may argue to the results that the region is not well covered by instruments in order to record all the earthquakes. But as we mention in the present text we processing aftershocks sequences which their main shock is greater than or equal to 7.0. But Aleutians belong both in U.S.A. and Russia. The Aleutians belonged to Russia show an unusual behaviour and the c-parameter is equal to 0.827 , while k-parameter is equal to -0.405 . This can be interpreted that the aftershock sequences are too severe in the earliest part of sequence and their total number of the aftershocks are the highest. However this observation is not so valid, because the results came from only 4 sequences.

Papua and Solomon islands show also high activity in the early part of the aftershock sequences occurred there, while k-parameter is in accord with the global mean.

The value of c parameter (0.550) and the small number of the k-parameter (-0.266) in Middle America lead us to the conclusion the activity is not so high in the first part of the aftershock sequences in this region and the aftershock sequences released with short number of aftershocks. The same phenomenon is demonstrated in the west coast of U.S.A. and Canada as a whole region. The activity in the earliest part of aftershock sequences is the smallest among the examined regions and the total number of aftershocks in the sequence is small enough. Looking in details in this region we have one of the most studied areas of the world, California. California itself shows a total different behaviour and both parameters are in accord with the global averages $(\mathrm{c}=0.626$ and $\mathrm{k}=-0.339)$. On the other side of American continent is the Caribbean loop which shows the same characteristics as the west coast of U.S.A. and Canada, where the activity is small the earliest part of the sequence $(\mathrm{c}=0.587)$ and the total number of aftershocks in a sequence is small, $(\mathrm{k}=-0.287)$, as well. The temporal behaviour of aftershock sequence in southern California during the time interval 1933-1988 was examined by Kisslinger and Jones (1991). They estimated the parameters c and k (with its standard errors) and they found similar values with ours, presented here. 
Two regions Taiwan as well as Marianas islands exhibit values of parameter $\mathrm{c}$ around the global average but both have a short total number of aftershocks in a sequence, as they listed in table (2). The $\mathrm{k}$-parameter in Taiwan is the shortest among the examined regions.

The tectonic setting and the mode of faulting are factors other than the fault surface properties that might control the behaviour of the sequences. Narteau et al. (2008) analyze the temporal properties of Californian mainshocks. They found that the c-parameter is a decreasing function of the magnitude of aftershocks and that it varies across different types of faulting. They also suggested that the time delay before the onset of the power -law aftershock decay rate is in average shorter for earthquake occurred in thrust than the normal faults. For earthquakes which generated in strike-slip faults this time delay takes an intermediate value.

The results illustrated here is very useful not only from theoretical point of view, but they have practical meaning, as well. Rescue teams must have knowledge about the frequency of aftershocks when they operate in collapsed structures, especially in the first hours after the main shock.

\section{References}

Coral, A., 2007. Statistical features of earthquake temporal occurrence. Lect. NotesPhys. 705, 191221.

Felzer, K.R. and Bronsky, E.E., 2006. Decay of aftershock density with distance indicates triggering by dynamic stress. Nature 441, 735-738.

Kagan, Y.Y. and Houston, H, 2005. Relation between mainshock rupture process and Omori's law for aftershock moment release rate. Geophys. J. Int. 163, 1039-1048.

Kisslinger, C., L. M. and Jones, L., 1991. Properties of aftershock sequences in southern

California. J. Geophys. Res. 96, 11, 947-11, 958.

Lolli, B. and Gasperini, P., 2006. Comparing different models of aftershock rate decay: The role of the catalog. Tectonophysics 423, 43-59.

Narteau, C., Shebalin, P. and Holschneider, M., 2002. Temporal limits of the power law aftershock decay rate. J. Geophys. Res.107 B12, 2359.

Narteau, C., Shebalin, P. and Holschneider, M., 2008.The onset of the aftershock decay rate across different stress regimes. Geophys. Res. Abstrs. 10, EGU2008-A-05624.

Omori, F., 1895. On the aftershocks of earthquakes. J. Coll. Sci. Imp. Univ. Tokyo 7, 111-200.

Page, B., 1968. Aftershocks and micro-aftershocks of great Alaska earthquake of 1964. Bull. Seism. Soc. Am.58, 1131-1168.

Parsons, T., 2002. Global Omori law decay of triggered earthquakes: Large aftershocks outside the classical aftershock zone. J. Geophys. Res.107, B9, pp. ESE9.1-ESE9.20.

Ranalli, G., 1969. A statistical study of aftershock sequences. Ann. Geofisica 22, 359-397.

Reasenberg, P.A. and Jones, L.M., 1989. Earthquake hazard after a mainshock in California. Science 243, 1173-1176.

Reasenberg, P.A. and Jones, L.M., 1994. Earthquake aftershocks update. Science 265, 1251-1252.

Shcherbakov, R. Turcotte, D.L. and Rudle, J.B., 2006. Scaling properties of the Parkfield aftershock sequences. Bull. Seismol. Soc. Am. 96, S376-S384.

Tajima, F. and Kanamori, H., 1985. Global survey of aftershock area expansion patterns. Phys. Earth planet. Inter.40, 77-134. 
Tsapanos, T.M., 1990a. Spatial distribution of the difference between the magnitudes of the main shock and the largest aftershock in the circum-Pacific belt. Bull. Seism. Soc. Am.80, 1180-1189.

Tsapanos, T.M., 1990b. B-Values of two tectonic parts in the circum-Pacific belt. Pageoph 134, 229242.

Tsapanos, T.M., Karakaisis, G.F., Hatzidimitriou, P.M. and Scordilis, E.M. 1988. On the probability of the time of occurrence of the largest aftershock and the largest foreshock in seismic sequence. Tectonophysics149, 177-180.

Tsapanos, T.M., Moutafi, Z.D., Gabrielidis, J.N., Spyrou, T.D. and Papazachos, C.B., 1994. Properties of the globally distributed aftershock sequences" emphasis in the circum-Pacific belt. Bulletin of the Geological Society of Greece XXX/5, 151-158.

Utsu, T. 1961. A statistical study on the occurrence of aftershocks. Geophys. Mag. Tokyo 30, 521603.

Utsu, T. 1969. Aftershocks and earthquake statistics (I). J. Faculty Science Hokkaido Univ., 7, 521603.

Utsu, T., Ogata, Y. and Matsumura, R.S., 1995. The centenary of the Omori formula for a decay law of aftershocks activity, J Phys Earth 43, 1-33.

Vinogradov, S.D., 2008. Aftershock sequences as evidence for relaxation process in a region containing an earthquake source. Izvestiya Physics of the Solid Earth 44, 138-141. 